Full length article

\title{
Balance and fear of falling in subjects with Parkinson's disease is improved after exercises with motor complexity
}

\author{
Carla Silva-Batista ${ }^{\mathrm{a}, \mathrm{b}, *}$, Daniel M. Corcos $^{\mathrm{c}, \mathrm{d}}$, Hélcio Kanegusuku ${ }^{\mathrm{e}}$, Maria Elisa Pimentel Piemonte ${ }^{\mathrm{f}}$, \\ Lilian Teresa Bucken Gobbi ${ }^{g}$, Andrea C. de Lima-Pardini ${ }^{\mathrm{a}, \mathrm{h}, \mathrm{i}}$, Marco Túlio de Mello ${ }^{\mathrm{j}}$, \\ Claudia L.M. Forjaz ${ }^{\mathrm{e}}$, Carlos Ugrinowitsch ${ }^{\mathrm{a}}$ \\ ${ }^{a}$ Laboratory of Neuromuscular Adaptations to Strength Training, School of Physical Education and Sport, University of São Paulo at São Paulo, São Paulo, Brazil \\ ${ }^{\mathrm{b}}$ School of Arts, Sciences and Humanities, University of São Paulo, Brazil \\ ${ }^{\mathrm{c}}$ Department of Physical Therapy \& Human Movement Sciences, Northwestern University, Chicago, Illinois, USA \\ d Department of Neurological Sciences, Rush University Medical Center, Chicago, Illinois, USA \\ e Exercise Hemodynamic Laboratory, School of Physical Education and Sport, University of São Paulo at São Paulo, São Paulo, Brazil \\ ${ }^{\mathrm{f}}$ Faculty of Medical Science, University of São Paulo, São Paulo, Brazil \\ ${ }^{g}$ Posture and Gait Studies Lab, São Paulo State University at Rio Claro, Rio Claro, Brazil \\ ${ }^{\mathbf{h}}$ Human Motor Systems Laboratory, School of Physical Education and Sport, University of São Paulo, São Paulo, Brazil \\ ${ }^{\mathrm{i}}$ LIM-44, Department of Radiology, University of São Paulo, São Paulo, Brazil \\ ${ }^{\mathbf{j}}$ Department of Psychobiology, Center for Psychobiology and Exercise Studies University Federal de São Paulo, São Paulo, Brazil
}

\section{A R T I C L E I N F O}

\section{Keywords:}

Resistance training

Unstable device

Postural instability

Fall

Cognitive impairment

Muscle strength

\begin{abstract}
A B S T R A C T
Resistance training with instability (RTI) uses exercises with high motor complexity that impose high postural control and cognitive demands that may be important for improving postural instability and fear of falling in subjects with Parkinson's disease (PD). Here, we hypothesized that: 1) RTI will be more effective than resistance training (RT) in improving balance (Balance Evaluation Systems Test [BESTest] and overall stability index [Biodex Balance System ${ }^{\circ}$ ) and fear of falling (Falls Efficacy Scale-International [FES-I] score) of subjects with Parkinson's disease (PD); and 2) changes in BESTest and FES-I after RTI will be associated with changes in cognitive function (Montreal Cognitive Assessment [MoCA] score - previously published) induced by RTI. Thirty-nine subjects with moderate PD were randomly assigned to a nonexercising control, RT, and RTI groups. While RT and RTI groups performed progressive RT twice a week for 12 weeks, the RTI group added progressive unstable devices to increase motor complexity of the resistance exercises. There were significant group $\times$ time interactions for BESTest, overall stability index, and FES-I scores $(P<0.05)$. Only RTI improved BESTest, overall stability index and FES-I scores, and RTI was more effective than RT in improving biomechanical constraints and stability in gait (BESTest sections) at post-training $(P<0.05)$. There were strong correlations between relative changes in BESTest and MoCA $(r=0.72, P=0.005)$, and FES-I and MoCA $(r=-0.75$, $P=0.003$ ) after RTI. Due to the increased motor complexity in RTI, RTI is recommended for improving balance and fear of falling, which are associated with improvement in cognitive function of PD.
\end{abstract}

\section{Introduction}

Postural instability, which is one of the most debilitating motor symptoms for subjects with Parkinson's disease (PD), increases the prevalence of falls $[1,2]$ and is associated with increased fear of falling $[3,4]$. Postural instability and fear of falling can lead to decreased mobility, physical activity avoidance, and social isolation, [4-7] resulting in reduced quality of life [8]. Despite being effective for bradykinesia, rigidity, and to some extent tremor, levodopa therapy and deep brain stimulation do not have a clear therapeutic effect on postural instability [9-11]. Thus, interventions able to mitigate postural instability and fear of falling in subjects with PD are needed.

Progressive resistance training (RT) is an effective intervention to improve bradykinesia [12,13] and muscle strength in subjects with PD [14-16]. Reductions in muscle strength increase the risk of falls in PD [2] and are negatively associated with postural impairments $[17,18]$ and fear of falling [3]. Therefore, RT-induced strength gains may improve both postural control and fear of falling in PD. Some studies have reported similar improvements in postural control when comparing RT and balance training $[19,20]$ and weak evidence that RT is more

\footnotetext{
* Corresponding author at: Department of Sport, University of São Paulo, Av. Prof. Mello Moraes, 65, São Paulo, SP, 05508-030, Brazil.

E-mail address: csilvabatista@usp.br (C. Silva-Batista).
} 
beneficial than balance training on postural control [21]. On the other hand, it has been suggested that combining RT with balance or taskspecific functional training may be more effective to improve postural control than RT alone in subjects with PD [14].

Recently, we found that compared to RT alone, RT performed on unstable devices (Resistance Training with Instability [RTI]) improved clinical (i.e., mobility, motor signs, cognitive function, and quality of life) [22], neuromuscular [23], and spinal inhibitory mechanisms outcomes [24] in subjects with PD. RTI requires not only muscle strength but also postural control while performing resistance exercises with unstable devices (e.g., BOSU ${ }^{\diamond}$ and balance disc) due to the concomitant and progressive increases in load/resistance and degree of instability over time (i.e., high motor complexity) [22], which may impose a greater challenge to postural control and higher cognitive demand than RT alone. Taken together, we hypothesized that RTI would be more effective than RT to improve balance and fear of falling of these subjects. In addition, it has been showed that cognitive function has a strong association with postural instability/gait disturbance [25] and gait performance parameters [26], suggesting that improvements in cognition may also positively affect balance, and as a consequence decrease the fear of falling. As we have previously demonstrated that RTI improved cognitive function in subjects with PD [22], we hypothesized that changes in cognition induced by RTI can be associated with changes in balance and fear of falling; however, these hypotheses require further testing.

Therefore, the purposes of this randomized controlled trial were: a) to compare the effects of RT and RTI on balance and fear of falling in moderate subjects with PD; and b) to examine the association between the changes in balance and fear of falling and the changes in cognitive function previously published [22].

\section{Methods}

\subsection{Subjects}

All of the subjects with PD were recruited from the Brazil Parkinson Association. The diagnosis of idiopathic PD was confirmed by a movement disorders specialist in accordance with UK Parkinson's Disease Society Brain Bank diagnostic criteria [27]. Eligibility criteria were: I) Hoehn and Yahr stage between 2 and 3, II) stable medication, III) age between 50 and 80 years, IV) not being engaged in any exercise training (e.g., aerobic and/or resistance training) in the past three years, V) not presenting with a neurological disorder other than PD, VI) not having significant arthritis, cardiovascular disease, and cognitive impairment by Mini-Mental State Examination (score < 23) [28]. The University's Ethical Committee (approval number - 2011/12) approved the experimental procedures associated with the present trial, which was registered at the National Clinical Trial (www.ensaiosclinicos.gov. br; RBR-53S3RK). Subjects signed an informed consent form after being fully informed of experimental procedures involved in the present study.

\subsection{Procedures}

We conducted the instability resistance training trial in PD (IRTT-PD [prospective, single center, parallel-group, randomized controlled trial]) between March 2013 and September 2014. Importantly, balance and fear of falling are secondary outcomes of our IRTT-PD study. The primary outcome measures have been previously published [22]. Subjects were assessed in the clinically "on" state (fully medicated) within 1.5 to $2 \mathrm{~h}$ of taking their morning dose of dopaminergic drugs. Balance, body stability, fear of falling, cognitive function, and lower limb force production capacity were assessed at baseline and at the end of experimental period (i.e., 12 weeks), in the same order and at the same time of day (in the morning). A physical therapist, masked to the experimental design, assessed balance, fear of falling and cognitive function indices on two consecutive days. On the first day, the cognitive function outcome (Montreal Cognitive Assessment [MoCA]) was assessed. On the second day, balance was assessed using both the Balance Evaluation Systems Test (BESTest), and the Biodex Balance System (i.e. overall stability index), and fear of falling was assessed using the Falls Efficacy Scale-International (FES-I). BESTest was chosen as a clinical balance outcome because this test is widely used in clinical practice, valid, reliable, low cost, and assess several underlying systems involved in balance control $[29,30]$. Overall stability index estimated by the Biodex Balance System was chosen as a laboratory-based measure of balance, due to its high reliability and validity for an aged matched healthy population[31]. FES-I was selected as an index of fear of falling because it has the highest reliability index among the available tests used for subjects with PD [32]. Following, maximum ballistic voluntary isometric contraction (MBVIC) tests of the knee extensor and plantar flexor muscles of the most affected leg were performed to assess changes in peak torque [23]. Finally, subjects were classified into quartiles based on their timed-up-and-go test score. Subjects from each quartile were randomly assigned to the non-exercising control group (C), RT group, or RTI group [22].

\subsection{Outcome measures}

BESTest is comprised of 36 items grouped into six sections as follow: (I) biomechanical constraints, (II) stability limits/verticality, (III) anticipatory postural adjustments, (IV) reactive postural responses, (V) sensory orientation, and (VI) stability in gait. Total BESTest (BESTest total) score is obtained by dividing the actual score by the maximum score (i.e., 108 points) and, then multiplying by 100 . Individual section scores are obtained in a similar fashion. The closer the score to the maximum score the better is one's balance [29]. The BESTest total score and the BESTest sections scores were used for analysis.

Biodex Balance System (Biodex ${ }^{\circ}$, Inc., Shirley, NY, USA) is comprised of a movable balance platform that provides up to $20^{\circ}$ of surface tilt in a $360^{\circ}$ arc of motion. Subjects followed the complete fall risk protocol suggested by the Biodex Balance System ${ }^{\circ}$, which is consisted of 12 dynamic stability levels being level 12 the most rigid and level 1 the most unstable. The main outcome measure is the overall stability index that represents the total variance of the platform displacement (anterior/posterior and medial/lateral stability index), measured in degrees, with higher scores indicating worse postural stability [33,34]. The formula $\left(\mathrm{OSI}=\left[\left(\Sigma(0-\mathrm{Y})^{2}+\Sigma(0-\mathrm{X})^{2} \text {.number of samples }{ }^{-1}\right)\right]^{\wedge 0.5}\right)$, where $Y$ and $X$ represent the degree of platform tilt in the sagittal and frontal planes respectively, was used to calculate the overall stability index. Subjects performed three attempts and the average value of these attempts was used for analysis.

Subjects answered how concerned they were about the fear of falling if they had to perform 16 different activities. Responses were provided using a four-point scale (not at all, somewhat, fairly, or very concerned). Test score ranges from 16 to 64 (higher $=$ worse) [32]. The FES-I score was used for analysis.

MoCA was used to assess changes in cognitive function from pre- to post-training [35-37]. The assessment was conducted in a quiet room without distractions by a physical therapist trained in the administration of the MoCA questionnaire. MoCA's maximum score is 30 and a score of $\leq 25$ indicates mild cognitive impairment $[38,39]$. A point was added to the total score for individuals with 12 or fewer years of education. MoCA assesses seven cognitive domains, such as visuo-spatial and executive functions ( 5 points), naming ( 3 points), attention (6 points), language ( 3 points), abstraction ( 2 points), delayed recall ( 5 points), and orientation (6 points). The compound MoCA score was used for further analyses [35-37].

Peak torque of knee extensors and plantaflexors were assessed using Biodex System 4, Biomedical Systems ${ }^{\varpi}$, Newark, CA, USA as described previously [23]. In brief, subjects were seated in the isokinetic dynamometer chair in an upright position. Following, they performed a 


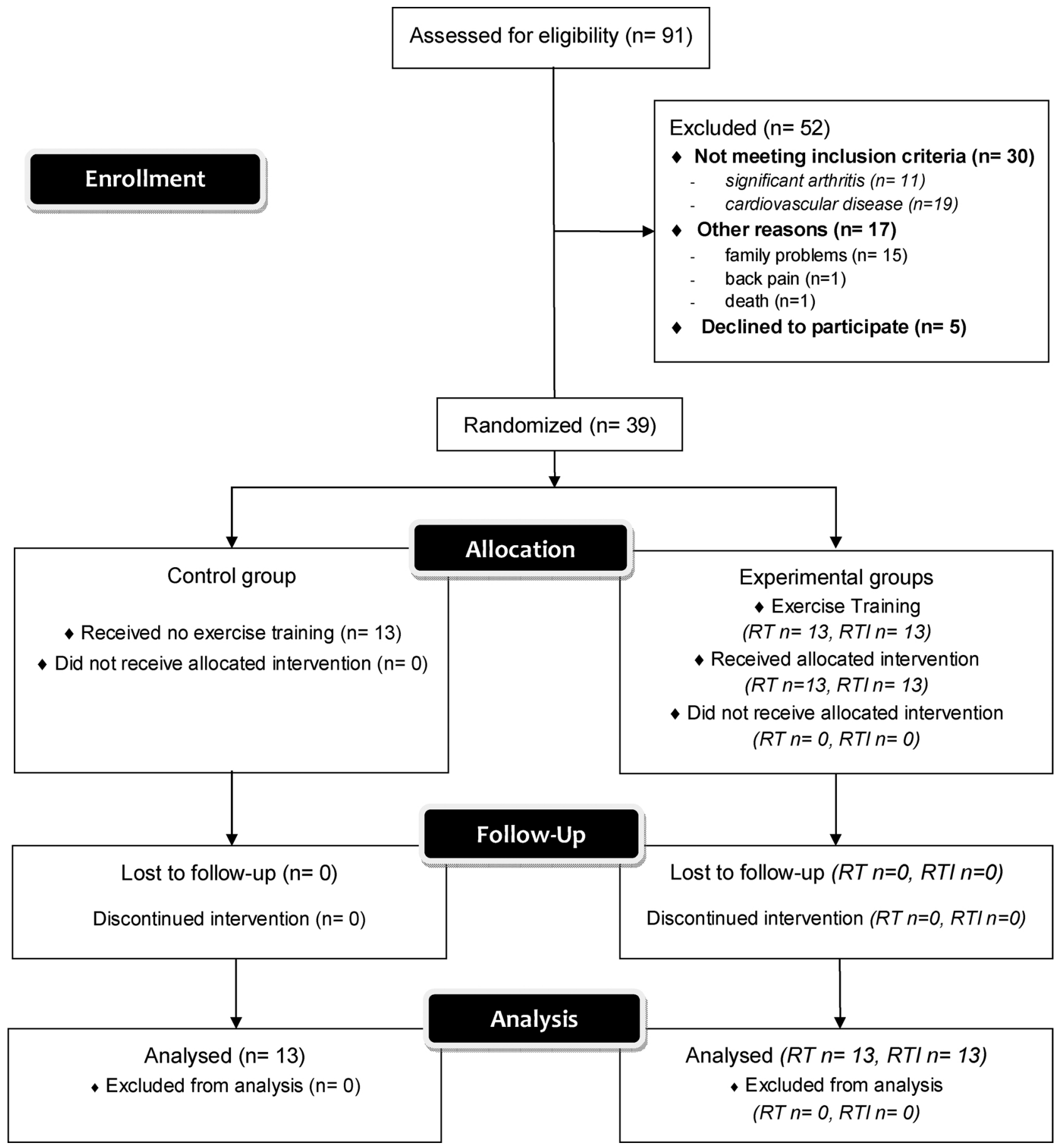

Fig. 1. The CONSORT diagram of the study. RT = resistance training, RTI = resistance training with instability group.

specific warm-up on the dynamometer, which consisted of 3-4 submaximal isometric contractions (50\% MBVIC) separated by $60 \mathrm{~s}$ rest intervals. After warm-up, subjects were asked to perform 5-7 progressive MBVICs of $5 \mathrm{~s}$ duration, with 2 min rest between them. Subjects were instructed to produce torque as fast as possible (MBVIC), hold at maximal torque for $2 \mathrm{~s}$, and then relax. Peak torque values of knee extensors and plantarflexors muscles were used for statistical analysis.

\subsection{Interventions}

Details of the RT and RTI protocols used in the IRTT-PD study have been published elsewhere [22]. In short, the $\mathrm{C}$ group did not perform any exercise training, but participated in bingo games and PD associated lectures once a week for $60 \mathrm{~min}$ at the Brazil Parkinson Association for 12 weeks. Both RT and RTI groups trained twice a week (non-consecutive days) for 12 weeks (24 training sessions). Training load progressed from high-volume low-intensity to low-volume highintensity loads in an attempt to maximize training adaptations over the training period [40]. RT and RTI consisted of conventional lower limb (i.e., half-squat, plantar flexion, and leg-press) and upper limb (latissimus dorsi pulldown and chest press) resistance exercises. For the RTI group, the degree of instability of the instability devices used when performing the exercises also increased throughout the experimental period (i.e., from the least to the most unstable devices) [22]. An unstable device was changed to a more unstable one whenever subjects decreased body sway considerably (i.e. ability to balance the body on 
the device, without presenting large excursions of the center of mass in the anteroposterior and mediolateral axes - visual inspection) and force production increased abruptly while performing the selected resistance exercises. If subjects were unable to increase training load due to the greater instability of the new unstable device, training load from the session prior to changing devices was used. Unstable devices (i.e., balance pad, dyna discs, balance discs, BOSU, and Swiss ball) were placed between the bases of support of subject (i.e., the body area responsible for sustaining most of his/her body weight and/or on the point of force application) and each resistance exercise [22]. Two researchers monitored all of the training sessions.

\subsection{Statistical analysis}

Initially, data were analyzed for normality (Shapiro-Wilk) and the presence of outliers (Box-plots). Subsequently, a mixed model was performed for each outcome (BESTest total score, BESTest section scores, overall stability index, FES-I score, MoCA score, peak torque of knee extensors and plantaflexors) having group (C, RT, and RTI) and time (pre and post) as fixed factors, and subjects with PD as a random factor [41]. Whenever a significant $F$-value was obtained, a post-hoc test with a Tukey's adjustment was performed. Within-group (pre - to post - changes) and between-groups (post - changes) ES were calculated using Cohen's d [42] for each outcome. ESs were classified as small (ES $\leq$ 0.49), medium (ES 0.50-0.79), and large (ES $\geq 0.80$ ). Person product-moment correlation was implemented to determine the relationship between the relative changes in BESTest total score and the relative changes in FES-I score. Correlations between the relative changes in BESTest total score, BESTest section scores, and FES-I scores, and relative changes in MoCA score were also estimated. As multiple correlations were estimated, a Bonferroni correction was implemented to decrease type I error rates $\left(P \leq 0.005\right.$ number of correlations $\left.{ }^{-1}\right)$. The significance level was set at $P \leq 0.05$. Results are expressed as mean \pm SD. SAS $9.2^{\circ}$ software (Institute Inc., Cary, NC, USA) was used to perform the statistical analyses. We also calculated the minimal detectable change $\left(\mathrm{MDC}_{95}=1.96 \times \sqrt{ } 2 \times\right.$ standard error of measurement) using data from the $\mathrm{C}$ group (pre and post). Minimal detectable change is the minimal change in a dependent variable between two points in time that indicates a true statistical change beyond random measurement error [43].

\section{Results}

\subsection{Subjects characteristics}

Ninety-one subjects volunteered to participate in this study and signed the written consent. Thirty subjects did not fulfill inclusion criteria (significant arthritis and cardiovascular disease) and 15 had family problems that precluded their participation. Thus, 46 subjects performed baseline testing, but one had back pain, one died, and 5 did not want to continue in the study. Thus, 39 subjects, 13 in each group, comprised the final sample (Fig. 1). The characteristics of the subjects with PD are presented in Table 1. There were no between-groups differences in demographic, anthropometric, and clinical characteristics at baseline $(P>0.05)$.

\subsection{BESTest total score}

At pre-training there were no between-group differences in the BESTest total score $(P>0.05)$. There was a significant group $\times$ time interaction for BESTest total score $\left(F_{[2,36]}=47.28, P<0.0001\right)$. The RTI group significantly increased the BESTest total score at posttraining (mean difference $[\mathrm{MD}]=18 \%$; 95\% confidence interval $[\mathrm{CI}]=12.7$ to $23.4 ; P<0.001 ; \mathrm{ES}=1.04)$ while the RT group showed no significant changes ( $\mathrm{MD}=2.9 \% ; \mathrm{CI}=-2.4$ to $8.2 ; P=0.579$; $\mathrm{ES}=0.24)$. The $\mathrm{C}$ group decreased BESTest total score at post-training
Table 1

Demographic, anthropometrical, and clinical values of the patients with Parkinson's disease by group at baseline. Mean $\pm \mathrm{SD}$.

\begin{tabular}{|c|c|c|c|}
\hline & $C(n=13)$ & $\mathrm{RT}(\mathrm{n}=13)$ & RTI $(\mathrm{n}=13)$ \\
\hline \multicolumn{4}{|l|}{ Demographic } \\
\hline Men/women (number) & $9 / 4$ & $10 / 3$ & $10 / 3$ \\
\hline Age (years) & $64.2 \pm 8.3$ & $64.1 \pm 9.1$ & $64.2 \pm 10.6$ \\
\hline Educational level (years) & $8.7 \pm 2.1$ & $8.5 \pm 2.5$ & $8.1 \pm 3.1$ \\
\hline \multicolumn{4}{|l|}{ Anthropometrical } \\
\hline Body mass (kg) & $69.2 \pm 11.4$ & $70.8 \pm 10.1$ & $71.3 \pm 8.2$ \\
\hline Height (cm) & $1.69 \pm 0.1$ & $1.68 \pm 0.2$ & $1.69 \pm 0.2$ \\
\hline Body mass index $\left(\mathrm{kg} / \mathrm{m}^{2}\right)$ & $24.3 \pm 3.8$ & $25.5 \pm 5.2$ & $25.0 \pm 3.0$ \\
\hline \multicolumn{4}{|l|}{ Clinical } \\
\hline $\begin{array}{l}\text { Mini-Mental State } \\
\text { Examination (score) }\end{array}$ & $28.5 \pm 1.8$ & $28.5 \pm 1.9$ & $28.8 \pm 1.7$ \\
\hline Range & $25-30$ & $25-30$ & $24-30$ \\
\hline $\begin{array}{l}\text { Years since diagnosis } \\
\quad \text { (years) }\end{array}$ & $10.7 \pm 6.1$ & $9.6 \pm 3.9$ & $10.5 \pm 4.1$ \\
\hline Range & $5-20$ & $6-20$ & $5-18$ \\
\hline $\begin{array}{l}\text { Hoehn and Yahr staging } \\
\text { scale (a.u) }\end{array}$ & $2.5 \pm 0.4$ & $2.5 \pm 0.5$ & $2.5 \pm 0.4$ \\
\hline 2 & 5 & 7 & 4 \\
\hline 2.5 & 4 & 0 & 4 \\
\hline 3 & 4 & 6 & 5 \\
\hline UPDRS-III (range $=0-108$ ) & $43.4 \pm 8.6$ & $43.7 \pm 13.4$ & $45.1 \pm 8.2$ \\
\hline Range & $29.2-57.7$ & $20-60.2$ & $32.5-59.7$ \\
\hline $\begin{array}{l}\text { L-Dopa equivalent units } \\
\qquad\left(\mathrm{mg} \mathrm{day}^{-1}\right)\end{array}$ & $796.7 \pm 151.3$ & $835.8 \pm 287.0$ & $875.9 \pm 223.4$ \\
\hline Range & $666-1082$ & $466-1257$ & $507-1174$ \\
\hline
\end{tabular}

$\mathrm{C}=$ control group; $\mathrm{RT}=$ resistance training group; $\mathrm{RTI}=$ resistance training with instability group; UPDRS-III = Unified Parkinson's Disease Rating Scale part III motor subscale.

$(\mathrm{MD}=-6.0 \% ; \mathrm{CI}=-11.4$ to $-0.7 ; P=0.018 ; \mathrm{ES}=-0.25)$. Post hoc analysis revealed that RTI obtained significantly higher BESTest total score than $\mathrm{C}$ group at post-training ( $\mathrm{MD}=15.9 \%$; $\mathrm{CI}=0.2$ to 31.5; $P<0.0001$; ES $=1.23$ ) (Table 2). Importantly, the minimal detectable change of BESTest total score obtained from $\mathrm{C}$ group, using pre- and post-test results, was $6.4 \%$.

\subsection{BESTest section}

At pre-training there were no between-group differences in any of the BESTest sections $(P>0.05)$. There were significant group $\times$ time interactions for the following BESTest section scores at post-training: biomechanical constraints $\left(F_{[2,36]}=43.19, P<0.001\right)$, limits of stability/verticality $\left(F_{[2,36]}=12.00, P<0.001\right)$, anticipatory postural adjustments $\left(F_{[2,36]}=12.15, P<0.001\right)$, reactive postural responses $\left(F_{[2,36]}=12.00, P<0.002\right)$, and stability in gait $\left(F_{[2,36]}=34.21\right.$, $P<0.001)$. The RTI group significantly improved biomechanical constraints $(\mathrm{MD}=39.4 \% ; \mathrm{CI}=29.5$ to $49.3 ; P=0.001 ; \mathrm{ES}=2.09$ ), limits of stability/verticality $(\mathrm{MD}=21.5 \% ; \quad \mathrm{CI}=10.8$ to 32.3 ; $P<0.001 ; \quad$ ES $=0.97), \quad$ anticipatory postural adjustments $(\mathrm{MD}=14.1 \% ; \mathrm{CI}=5.7$ to $22.4 ; P=0.002 ; \mathrm{ES}=0.72)$, and stability in gait $(\mathrm{MD}=27.1 \%$; $\mathrm{CI}=17.1$ to $36.6 ; P<0.001$; $\mathrm{ES}=1.51$ ) while the $C$ group worsened the reactive postural responses $(\mathrm{MD}=-5.9 \%$; $\mathrm{CI}=-11.3$ to $-0.5 ; P=0.021 ; \mathrm{ES}=-0.36$ ), from pre- to posttraining assessments. The RT group showed no significant changes at post-training $(P>0.05)$. Post hoc analysis revealed higher BESTest section scores for the RTI group than $\mathrm{C}$ group at post-training: biomechanical constraints $(\mathrm{MD}=33.3 \%$; $\mathrm{CI}=9.9$ to $56.6 ; P=0.016$; $\mathrm{ES}=1.43)$, limits of stability/verticality $(\mathrm{MD}=26.1 \% ; \mathrm{CI}=2.0$ to 49.9; $P=0.026$; $\mathrm{ES}=0.99$ ), and anticipatory postural adjustments $(\mathrm{MD}=20.9 \% ; \mathrm{CI}=0.1$ to $41.9 ; P=0.050 ; \mathrm{ES}=1.07)$. Post hoc analysis also revealed significant higher BESTest section scores for the RTI when compared to RT at post-training: biomechanical constraints $(\mathrm{MD}=29.2 \% ; \mathrm{CI}=5.8$ to $52.5 ; P=0.007 ; \mathrm{ES}=1.55)$ and stability in gait $(\mathrm{MD}=21.9 \%$; $\mathrm{CI}=0.6$ to $43.6 ; P=0.041 ; \mathrm{ES}=0.97$ ) (Table 2 ). 
Table 2

Balance, fear of falling, cognitive function, and peak torque outcomes in the pre- and post-training assessments for each group of subjects with Parkinson's disease (mean \pm SD).

\begin{tabular}{|c|c|c|c|c|c|c|}
\hline \multirow[t]{2}{*}{ Outcomes } & \multicolumn{2}{|l|}{$C(n=13)$} & \multicolumn{2}{|l|}{ RT (n = 13) } & \multicolumn{2}{|l|}{ RTI $(\mathrm{n}=13)$} \\
\hline & Pre-training & Post-training & Pre-training & Post-training & Pre-training & Post-training \\
\hline $\begin{array}{l}\text { BESTest total score (\%) } \\
\text { BESTest section }\end{array}$ & $75.9 \pm 13.3$ & $71.9 \pm 13.5^{\mathrm{a}}$ & $76.3 \pm 12.2$ & $79.2 \pm 14.2$ & $73.6 \pm 17.4$ & $91.8 \pm 8.7^{\mathrm{a}, \mathrm{b}}$ \\
\hline I. Biomechanical constraints (\%) & $63.1 \pm 22.9$ & $61.0 \pm 26.7$ & $56.9 \pm 22.5$ & $65.1 \pm 20.7$ & $54.9 \pm 20.4$ & $94.4 \pm 8.0^{\mathrm{a}, \mathrm{b}, \mathrm{c}}$ \\
\hline II. Limits of stability/verticality (\%) & $73.6 \pm 26.1$ & $73.3 \pm 26.6$ & $79.9 \pm 17.3$ & $80.6 \pm 18.0$ & $77.7 \pm 22.9$ & $99.3 \pm 1.5^{\mathrm{a}, \mathrm{b}}$ \\
\hline III. Anticipatory postural adjustments (\%) & $80.3 \pm 19.2$ & $75.6 \pm 18.7$ & $81.2 \pm 18.6$ & $81.6 \pm 19.7$ & $82.5 \pm 20.6$ & $96.6 \pm 10.5^{\mathrm{a}, \mathrm{b}}$ \\
\hline IV. Reactive postural responses (\%) & $83.3 \pm 16.7$ & $77.4 \pm 20.0^{*}$ & $94.4 \pm 10.6$ & $94.9 \pm 10.6$ & $81.6 \pm 22.8$ & $82.1 \pm 21.9$ \\
\hline V. Sensory orientation (\%) & $70.3 \pm 23.8$ & $70.3 \pm 22.5$ & $85.6 \pm 15.8$ & $86.2 \pm 16.8$ & $82.6 \pm 18.9$ & $88.2 \pm 14.1$ \\
\hline VI. Stability in gait (\%) & $81.0 \pm 18.3$ & $71.8 \pm 15.3$ & $60.1 \pm 16.9$ & $67.4 \pm 22.8$ & $62.3 \pm 15.9$ & $89.4 \pm 18.3^{\mathrm{a}, \mathrm{c}}$ \\
\hline Overall stability index $\left({ }^{\circ}\right)$ & $2.3 \pm 0.8$ & $2.5 \pm 1.1$ & $2.4 \pm 1.1$ & $2.0 \pm 1.1$ & $2.6 \pm 0.9$ & $1.3 \pm 0.4^{\mathrm{a}, \mathrm{c}}$ \\
\hline FES-I (score) & $32.6 \pm 7.7$ & $35.2 \pm 8.3$ & $31.8 \pm 11.5$ & $29.9 \pm 12.3$ & $33.2 \pm 6.1$ & $29.8 \pm 7.2^{\mathrm{a}}$ \\
\hline MoCA (score) & $22.7 \pm 5.7$ & $21.6 \pm 6.5$ & $21.8 \pm 4.3$ & $22.2 \pm 3.0$ & $20.8 \pm 3.2$ & $26.8 \pm 2.4^{\mathrm{a}, \mathrm{b}}$ \\
\hline Peak torque of knee extensors $(\mathrm{N} \mathrm{m})$ & $76.5 \pm 32.6$ & $73.4 \pm 32.4$ & $79.8 \pm 25.0$ & $114.6 \pm 24.5^{\mathrm{a}, \mathrm{b}}$ & $77.9 \pm 30.2$ & $112.4 \pm 41.7^{\mathrm{a}, \mathrm{b}}$ \\
\hline Peak torque of plantarflexors $(\mathrm{N} \mathrm{m})$ & $51.1 \pm 24.2$ & $45.6 \pm 23.0$ & $49.6 \pm 24.9$ & $78.5 \pm 26.6^{\mathrm{a}, \mathrm{b}}$ & $53.2 \pm 24.6$ & $103.7 \pm 24.1^{\mathrm{a}, \mathrm{b}}$ \\
\hline
\end{tabular}

$\mathrm{C}=$ Control; $\mathrm{RT}=$ Resistance Training; RTI = Resistance Training with Instability

a Different from pre-training values $(P \leq 0.05)$

b Different from post-training values of the $C$ group $(P \leq 0.05)$.

${ }^{\mathrm{c}}$ Different from post-training values of the RT group $(P \leq 0.05)$.

\subsection{Overall stability index}

At pre-training there were no between-group differences in the overall stability index $(P>0.05)$. There was a significant group $\times$ time interaction for the overall stability index $(F$ $[2,36]=28.60, P<0.001)$. The RTI group significantly decreased the overall stability index after training $\left(\mathrm{MD}=-1.3^{\circ}\right.$; IC $=-1.8$ to -0.9 ; $P<0.001$; ES $=-1.46)$ while both RT (MD $=-0.3^{\circ}$; IC $=-0.1$ to $0.7 ; P=0.275 ; \mathrm{ES}=-0.30$ ) and $\mathrm{C}$ groups $\left(\mathrm{MD}=-0.1^{\circ} ; \mathrm{IC}=-0.6\right.$ to $0.2 ; P=0.787$; ES $=-0.25$ ) showed no significant changes at posttraining. Post hoc analysis revealed that RTI presented significantly lower overall stability index than $\mathrm{C}$ group at post-training $\left(\mathrm{MD}=-1.2^{\circ} ; \mathrm{IC}=-2.3\right.$ to $\left.-0.1 ; P=0.014 ; \mathrm{ES}=-1.18\right)$ (Table 2$)$.

\subsection{FES-I total score}

At pre-training there were no between-group differences in the FES-I score $(P>0.05)$. There was a significant group $\times$ time interaction for FES-I score $\left(F_{[2,36]}=11.32, P=0.002\right)$. The RTI group significantly decreased FES-I scores after training (MD $=-3.3$ score; $\mathrm{CI}=-6.0$ to $-0.5 ; P=0.001 ; \mathrm{ES}=-0.54$ ) while both RT (MD $=-1.9$ score; $\mathrm{CI}=4.6$ to $-0.8 ; P=0.315 ; \mathrm{ES}=-0.17)$ and $\mathrm{C}$ groups $(\mathrm{MD}=2.6$ score; $\mathrm{CI}=-0.1$ to $5.3 ; P=0.073$; $\mathrm{ES}=0.34$ ) showed no significant changes at post-training. Post hoc analysis revealed no between-group differences in FES-I score at post-training $(P>0.05)$ (Table 2$)$.

\subsection{MoCA score}

A significant group $\times$ time interaction was observed for the compound MoCA scores $\left(F_{[2,36]}=41.00, P<0.0001\right)$. The RTI group significantly decreased compound MoCA scores at post-training ( $\mathrm{MD}=6.0$ score; $\mathrm{CI}=4.2$ to $7.7 ; P<0.001$; $\mathrm{ES}=1.90$ ) while the RT group (MD $=0.4$ score; $\mathrm{CI}:-2.2$ to $1.2 ; P=0.996 ; \mathrm{ES}=0.11$ ) and the $\mathrm{C}$ group (MD $=-1.1$ score; $\mathrm{CI}=-2.8$ to $0.6 ; P=0.446$; $\mathrm{ES}=0.19$ ) presented no significant changes. Compound MoCA scores for the RTI were greater than scores for the $\mathrm{C}$ groups at post training (MD $=-5.2$ score; $\mathrm{CI}=-10.4$ to $0.01 ; P=0.050 ; \mathrm{ES}=0.80$ ) (Table 2). Results previously published [22].

\subsection{Peak torque of knee extensors and plantarflexors}

A significant group $\times$ time interaction was observed for knee extensors $\quad(F \quad[2,36]=14.92, \quad P=0.001)$ and plantarflexors $(F$ $\left.{ }_{[2,36]}=47.91, P<0.0001\right)$ peak torque. Knee extensors and plantarflexors peak torque increased significantly in the RT $(\mathrm{MD}=34.7 \mathrm{~N} \mathrm{~m}$; $\mathrm{CI}=17.8$ to $51.7 ; \quad P<0.0001 ; \quad \mathrm{ES}=1.39$ and $\mathrm{MD}=28.8 \mathrm{~N} \mathrm{~m}$; $\mathrm{CI}=16.5$ to $41.1 ; P<0.0001 ; \mathrm{ES}=1.16$, respectively) and $\mathrm{RTI}$ groups $(\mathrm{MD}=34.5 \mathrm{~N} \mathrm{~m} ; \mathrm{CI}=17.5$ to $51.4 ; P<0.0001 ; \mathrm{ES}=1.14$ and $\mathrm{MD}=50.4 \mathrm{~N} \mathrm{~m} ; \mathrm{CI}=32.2$ to $78.7 ; P<0.0001 ; \mathrm{ES}=2.05$, respectively) at post-training. In addition, between-group differences were observed at post-training. Peak torque values of knee extensors were greater in the RT $(\mathrm{MD}=41.2 \mathrm{~N} \mathrm{~m} ; \mathrm{CI}=3.9$ to $78.5 ; P<0.0001$; $\mathrm{ES}=1.27)$ and RTI groups $(\mathrm{MD}=39.0 \mathrm{Nm} ; \mathrm{CI}=1.7$ to 76.3 ; $P<0.0001 ; \mathrm{ES}=1.21)$ than $\mathrm{C}$ group. Similarly, peak torque values of plantarflexors were also greater in the $\mathrm{RT}(\mathrm{MD}=32.9 \mathrm{~N} \mathrm{~m}$; $\mathrm{CI}=3.8$ to $61.9 ; P<0.0001 ; \mathrm{ES}=1.43)$ and RTI groups $(\mathrm{MD}=25.1 \mathrm{~N} \mathrm{~m}$; $\mathrm{CI}=29.0$ to $87.0 ; P<0.0001 ; \mathrm{ES}=2.53$ ) than $\mathrm{C}$ group (Table 2 ). Results previously published [23].

\subsection{Correlations}

The RTI group presented strong and significant correlations between the relative changes in MoCA score and the relative changes in the following outcomes (Table 3): BESTest total score (Fig. 2A), BESTest anticipatory postural adjustments section (Fig. 2B), and FES-I score

Table 3

Correlations between relative changes in balance and cognitive function, and correlations between relative changes in fear of falling and cognitive function for each group of training of subjects with Parkinson's disease.

\begin{tabular}{|c|c|c|c|c|}
\hline \multirow[t]{3}{*}{ Outcomes } & \multirow{2}{*}{\multicolumn{2}{|c|}{$\begin{array}{l}\mathrm{RT}(\mathrm{n}=13) \\
\text { MoCA }(\%)\end{array}$}} & \multirow{2}{*}{\multicolumn{2}{|c|}{$\frac{\text { RTI }(\mathrm{n}=13)}{\text { MoCA }(\%)}$}} \\
\hline & & & & \\
\hline & $r$ & P value & $r$ & $P$ value \\
\hline $\begin{array}{l}\text { BESTest total score (\%) } \\
\text { BESTest section }\end{array}$ & 0.188 & 0.537 & 0.726 & $0.005^{\mathrm{a}}$ \\
\hline I. Biomechanical constraints (\%) & 0.069 & 0.822 & 0.124 & 0.684 \\
\hline II. Limits of stability/verticality (\%) & 0.280 & 0.353 & 0.673 & 0.011 \\
\hline III. Anticipatory postural adjustments (\%) & 0.078 & 0.799 & 0.816 & $0.000^{\mathrm{a}}$ \\
\hline IV. Reactive postural responses (\%) & 0.078 & 0.799 & 0.673 & 0.011 \\
\hline V. Sensory orientation (\%) & 0.078 & 0.799 & 0.469 & 0.105 \\
\hline VI. Stability in gait (\%) & 0.534 & 0.060 & 0.163 & 0.593 \\
\hline Overall stability index (\%) & -0.105 & 0.730 & -0.037 & 0.904 \\
\hline FES-I (\%) & -0.176 & 0.563 & -0.752 & $0.003^{\mathrm{a}}$ \\
\hline
\end{tabular}

$\mathrm{RT}=$ Resistance Training; RTI $=$ Resistance Training with Instability.

${ }^{\text {a }}$ Significant correlation $(P \leq 0.005)$. 

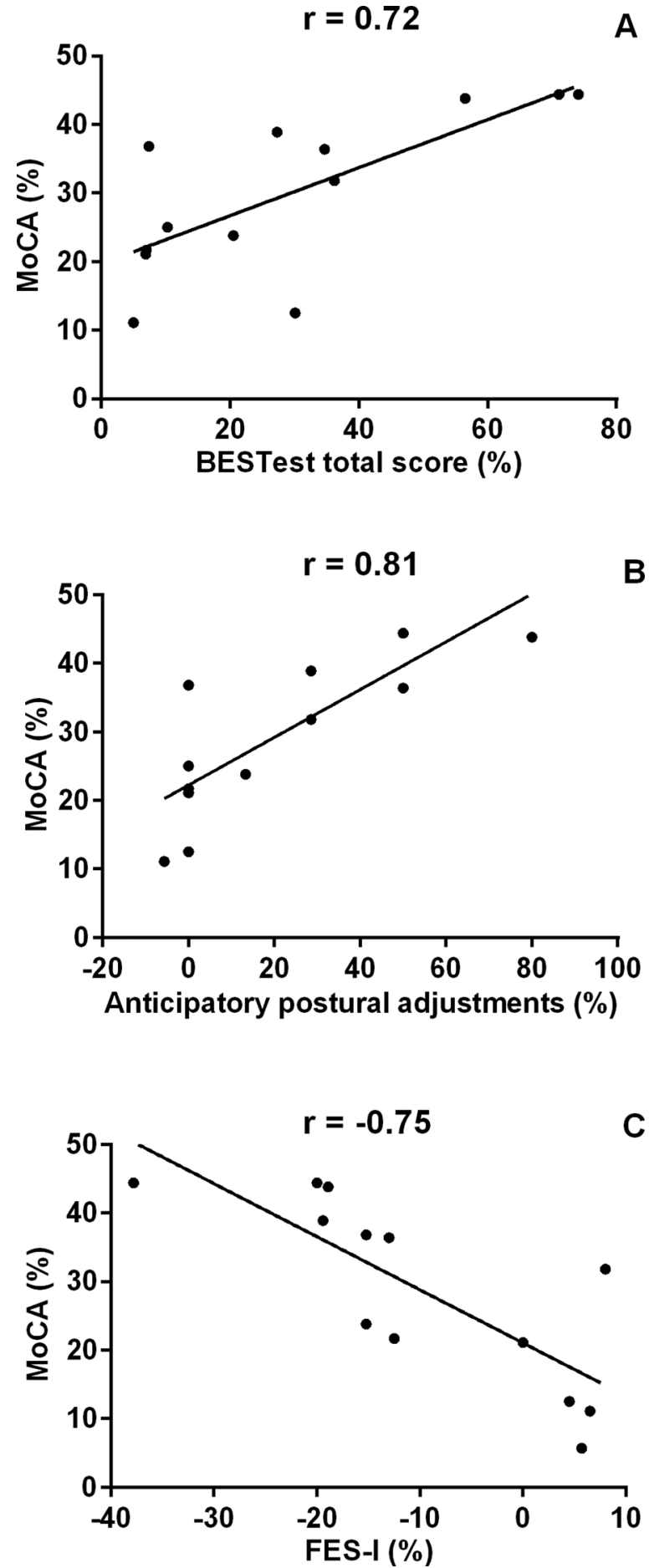

Fig. 2. Scatter plot and regression line between the relative changes in Montreal Cognitive Assessment (MoCA) and the relative changes in the scores of following outcomes: Balance Evaluation Systems Test (BESTest - A panel), anticipatory postural adjustments (B panel), and Falls Efficacy Scale-International (FES-I - C panel) for the resistance training with instability group.

(Fig. 2C). However, no significant correlations were found for the RT group (Table 3 ).

\subsection{Adverse effects and attendance}

No adverse effects were reported during the trial. Attendance to the protocol was high for both training groups $(23.6 \pm 0.5$ sessions $(98 \%)$ for RT and $23.3 \pm 0.7$ sessions (97\%) for RTI).

\section{Discussion}

This randomized controlled trial showed that only RTI improved BESTest score (total score and most section scores) and FES-I score producing medium to large ESs and it was more effective than RT in improving some BESTest section scores (biomechanical constraints and stability in gait) (Table 2) confirmed by large ES values. In addition, there were strong associations between BESTest and MoCA changes and between FES-I and MoCA changes, respectively, after RTI.

The positive effects of RTI on postural control observed herein can be therapeutically beneficial to subjects with PD. The improvement in BESTest score after RTI (i.e., mean difference $-18.2 \%$ ) was approximately 1.8 greater than the minimal detectable change (smallest difference in individual scores that represents true change beyond random measurement error) of $6.4 \%$ points on BESTest score observed in the $\mathrm{C}$ group of the present study. Importantly, we estimated the minimal detectable change of BESTest using the data from $C$ group because there are no available data for subjects with PD. BESTest was designed to test balance control, which is very complex and involves several different underlying systems responsible for functional balance [29]. RTI improved most of the BESTest sections, such as biomechanical constraints, limits of stability/verticality, anticipatory postural adjustments, and stability in gait. Furthermore, differences between RTI and RT groups at post-training were observed for biomechanical constraints and stability in gait section (Table 2).

Neuromuscular constraints on biomechanical systems, such as ankle or hip weakness and flexed postural alignment, limit the ability of subjects with PD to use the ankle strategy or compensatory steps to recover balance after, for instance, tripping $[44,45]$. We have demonstrated that RTI not only improved force production capacity (i.e., peak torque and rate of torque development) of the plantarflexors and knee extensors (Table 2) but also anticipatory postural adjustments and limits of stability/verticality, which may have positively affected the flexed postural alignment of subjects with PD. Thus, RTI seems to improve both flexed postural alignment and muscle weakness, inducing the required adaptations to improve biomechanical constraint scores observed herein; whereas RT increased only muscle strength, which was not sufficient to improve the biomechanical constraints. Regarding stability in gait, poor dynamic balance during gait seems to be due to impaired coordination between spinal locomotor and brain-stem postural sensorimotor programs [46]. Presynaptic inhibition is a powerful spinal mechanism associated with poor mobility and postural instability in PD [47]. We have also demonstrated that RTI was more effective than RT in causing plastic changes in the presynaptic inhibitory pathway [24], which may have contributed to improve postural instability in subjects with PD and stability in gait observed herein. Thus, progression in instability and load (i.e., RTI) can be deemed as more effective than progression in load only (i.e., RT) to improve subjects with PD' postural control. This concept received additional support from two recent meta-analyses showing no significant improvements in postural control following RT in subjects with PD [14,48].

Regarding fear of falling, the additional challenge of RTI over RT in controlling the position of the body's center of mass while performing resistance exercises may have decreased subjects' fear of falling. This suggestion is supported by reduction in FES-I values displayed on Table 2 for RTI. Previous studies have also demonstrated improvement in FES-I score in subjects with PD only after a challenging balance training [49]. Taking together, these findings support the notion that challenging training is necessary to improve the fear of falling. The questions identified in FES-I are not just limited to basic daily activities at home but also contain social activities usually performed in different environments. After RTI, subjects may become more confident in balance demanding tasks, such as walking in a crowded place or on a slippery or uneven surface. As walking ability is a major contributor to fear of falling in individuals with PD [50] it is possible that the improvement in stability in gait after RTI may also have contributed to 
decrease the fear of falling.

It is important to highlight that RTI has been shown to produce significant changes in MoCA score as previously published [22]. Studies have demonstrated that cognitive function has a high association with postural instability/gait disturbance [25] and gait performance parameters [26]. In the present study, we found significant correlations between relative changes in BESTest total score, BESTest anticipatory postural adjustments section, and FES-I scores, and relative changes in MoCA score. Cognitive dysfunction is a common non-motor feature of PD that contributes to reduced quality of life [51] and increased risk for disability and mortality [52,53]. Deficits in global cognitive function besides other cognitive domains (e.g., executive function memory, visuospatial processing, and phonemic fluency) were associated with deficits in posture and gait $[25,26]$. It has been suggested that cognitive deficits exacerbate and may even cause gait/balance impairment and increase the risk of falling, especially during more challenging situations [54]. Moreover, prefrontal lobe dysfunction has been linked to motor disability in subjects with PD [54-56]. Thus, the improvement in MoCA score previously reported after RTI may have contributed to the improvements in postural instability and fear of falling observed herein. In this sense, RTI emerges as an appealing adjunct therapeutic approach for PD, as it imposes high challenge to postural control and cognitive demand, which can be responsible for improving balance and fear of falling. Accordingly, it has been suggested that multimodality interventions, combining motor and cognitive therapies, should be incorporated into clinical practice to enable older adults and subjects to move safer and with a reduced fall risk [54].

\subsection{Study limitations}

The present study has some limitations. First, even though the present study presented robust changes in balance and fear of falling after RTI than after RT, the sample size of the present trial was small (13 subjects per group); thus, a larger randomized controlled clinical trial is needed to validate the reported benefits of the RTI on balance and fear of falling. Second, subjects were assessed in the clinically on state of their medication cycle, which reflects their typical state during daily life but may not reflect their true disease state. Third, it was not possible to observe the carryover effects of RTI on outcome at follow-up interval after the 12 weeks. Fourth, one may consider that having a standard instability training group could help determining if RTI effects observed herein were due to the combination of strength and balance training, or if balance training per se would be sufficient to produce similar adaptations. This suggestion was based on the findings that Tai Chi training was more effective than RT to improve balance impairments in PD patients [57] and there is weak evidence that RT is more beneficial than balance training on postural control [21]. However, this group would be a second "positive control group" as in our original trial RT group was considered as a "positive control". Accordingly, there is evidence that RT improves off medication motor signs, cognitive impairment, physical function, muscle strength, and quality of life $[16,58,59]$. Thus, additional trials are required to determine if RTI-induced benefits were due to the combination of strength and balance training, or only to the balance component of RTI.

\subsection{Conclusions}

This randomized controlled trial strongly supports the use of an innovative exercise intervention with high motor complexity (RTI) to improve balance and fear of falling in subjects with PD that are strongly associated with improvements in cognitive function.

\section{Conflict of interest}

The authors declared no potential conflicts of interest with respect to the research, authorship, and/or publication of this article. This manuscript has not been published and is not under consideration for publication elsewhere

\section{Acknowledgement}

The authors thank the subjects for their commitment to study, Associação Brasil Parkinson's staff, Center for Psychobiology and Exercise Studies, FAPESP (Fundação de Amparo à Pesquisa do Estado de São Paulo), CNPq (Conselho Nacional de Desenvolvimento Científico e Tecnológico), CAPES (Coordenação de Aperfeiçoamento de Pessoal de Nível Superior), and Prêmio Pembertom Coca-Cola Brasil. This study was supported by a grant from the FAPESP (2011/042423, 2012/ 03056-4, and 2013/04970-4), CAPES (3095/2015-00), and CNPQ (406609/2015-2).

\section{References}

[1] G.K. Kerr, C.J. Worringham, M.H. Cole, P.F. Lacherez, J.M. Wood, P.A. Silburn, Predictors of future falls in Parkinson disease, Neurology 75 (2010) 116-124.

[2] M.D. Latt, S.R. Lord, J.G. Morris, Fung vs. clinical and physiological assessments for elucidating falls risk in Parkinson's disease, Mov. Disord. 24 (2009) 1280-1289.

[3] M.K. Mak, M.Y. Pang, V. Mok, Gait difficulty, postural instability, and muscle weakness are associated with fear of falling in people with Parkinson's disease, Parkinsons Dis. 2012 (2012) 901721.

[4] A.L. Adkin, J.S. Frank, M.S. Jog, Fear of falling and postural control in Parkinson's disease, Mov. Disord. 18 (2003) 496-502.

[5] B.R. Bloem, Y.A. Grimbergen, M. Cramer, M. Willemsen, A.H. Zwinderman, Prospective assessment of falls in Parkinson's disease, J. Neurol. 248 (2001) 950-958.

[6] B.R. Bloem, J.P. van Vugt, D.J. Beckley, Postural instability and falls in Parkinson's disease, Adv. Neurol. 87 (2001) 209-223.

[7] J.G. Nutt, F.B. Horak, B.R. Bloem, Milestones in gait, balance, and falling, Mov. Disord. 26 (2011) 1166-1174.

[8] M. Michalowska, U. Fiszer, A. Krygowska-Wajs, K. Owczarek, Falls in Parkinson's disease. Causes and impact on patients' quality of life, Funct. Neurol. 20 (2005) $163-168$.

[9] J. Nantel, J.C. McDonald, H. Bronte-Stewart, Effect of medication and STN-DBS on postural control in subjects with Parkinson's disease, Parkinsonism Relat. Disord. 18 (2012) 285-289.

[10] A. Fasano, C.C. Aquino, J.K. Krauss, C.R. Honey, B.R. Bloem, Axial disability and deep brain stimulation in patients with Parkinson disease, Nat. Rev. Neurol. 11 (2015) 98-110.

[11] J.E. Visser, J.H. Allum, M.G. Carpenter, R.A. Esselink, J.D. Speelman, G.F. Borm, et al., Subthalamic nucleus stimulation and levodopa-resistant postural instability in Parkinson's disease, J. Neurol. 255 (2008) 205-210.

[12] F.J. David, J.A. Robichaud, D.E. Vaillancourt, C. Poon, W.M. Kohrt, C.L. Comella, et al., Progressive resistance exercise restores some properties of the triphasic EMG pattern and improves bradykinesia: the PRET-PD randomized clinical trial, J. Neurophysiol. 116 (2016) 2298-2311.

[13] L.E. Dibble, T.F. Hale, R.L. Marcus, J.P. Gerber, P.C. LaStayo, High intensity eccentric resistance training decreases bradykinesia and improves Quality Of Life in persons with Parkinson's disease: a preliminary study, Parkinsonism Relat. Disord. 15 (2009) 752-757.

[14] A. Tillman, M. Muthalib, A.M. Hendy, L.G. Johnson, T. Rantalainen, D.J. Kidgell, et al., Lower limb progressive resistance training improves leg strength but not gait speed or balance in Parkinson's disease: a systematic review and meta-analysis, Front. Aging Neurosci. 7 (2015) 40.

[15] L. Roeder, J.T. Costello, S.S. Smith, I.B. Stewart, G.K. Kerr, Effects of resistance training on measures of muscular strength in people with Parkinson's disease: a systematic review and meta-analysis, PLoS One 10 (2015) e0132135.

[16] D.M. Corcos, J.A. Robichaud, F.J. David, S.E. Leurgans, D.E. Vaillancourt, C. Poon, et al., A two-year randomized controlled trial of progressive resistance exercise for Parkinson's disease, Mov. Disord. 28 (2013) 1230-1240.

[17] J.R. Nocera, T. Buckley, D. Waddell, M.S. Okun, C.J. Hass, Knee extensor strength, dynamic stability, and functional ambulation: are they related in Parkinson's disease, Arch. Phys. Med. Rehabil. 91 (2010) 589-595.

[18] M. Nallegowda, U. Singh, G. Handa, M. Khanna, S. Wadhwa, S.L. Yadav, et al., Role of sensory input and muscle strength in maintenance of balance, gait, and posture in Parkinson's disease: a pilot study, Am. J. Phys. Med. Rehabil. 83 (2004) 898-908.

[19] M.A. Hirsch, T. Toole, C.G. Maitland, R.A. Rider, The effects of balance training and high-intensity resistance training on persons with idiopathic Parkinson's disease, Arch. Phys. Med. Rehabil. 84 (2003) 1109-1117.

[20] T. Toole, M.A. Hirsch, A. Forkink, D.A. Lehman, C.G. Maitland, The effects of a balance and strength training program on equilibrium in Parkinsonism: a preliminary study, NeuroRehabilitation 14 (2000) 165-174.

[21] C. Schlenstedt, S. Paschen, A. Kruse, J. Raethjen, B. Weisser, G. Deuschl, Resistance versus balance training to improve postural control in Parkinson's disease: a randomized rater blinded controlled study, PLoS One 10 (2015) e0140584.

[22] C. Silva-Batista, D.M. Corcos, H. Roschel, H. Kanegusuku, L.T. Gobbi, M.E. Piemonte, et al., Resistance training with instability for patients with 
Parkinson's disease, Med. Sci. Sports Exerc. 48 (2016) 1678-1687.

[23] C. Silva-Batista, D.M. Corcos, R. Barroso, F.J. David, H. Kanegusuku, C. Forjaz, et al., Instability resistance training improves neuromuscular outcome in Parkinson's disease, Med. Sci. Sports Exerc. 49 (2017) 652-660.

[24] C. Silva-Batista, E.C. Mattos, D.M. Corcos, J.M. Wilson, C.J. Heckman, $\mathrm{H}$. Kanegusuku, et al., Resistance training with instability is more effective than resistance training in improving spinal inhibitory mechanisms in Parkinson's disease, J. Appl. Physiol. 122 (2017) 1-10.

[25] V.E. Kelly, C.O. Johnson, E.L. McGough, A. Shumway-Cook, F.B. Horak, K.A. Chung, et al., Association of cognitive domains with postural instability/gait disturbance in Parkinson's disease, Parkinsonism Relat. Disord. 21 (2015) 692-697.

[26] G. Pal, J. O'Keefe, E. Robertson-Dick, B. Bernard, S. Anderson, D. Hall, Global cognitive function and processing speed are associated with gait and balance dysfunction in Parkinson's disease, J. Neuroeng. Rehabil. 13 (2016) 94.

[27] A.J. Hughes, S.E. Daniel, L. Kilford, A.J. Lees, Accuracy of clinical diagnosis of idiopathic Parkinson's disease: a clinico-pathological study of 100 cases, J. Neurol. Neurosurg. Psychiatry 55 (1992) 181-184.

[28] M.F. Folstein, S.E. Folstein, P.R. McHugh, Mini-mental state. A practical method for grading the cognitive state of patients for the clinician, J. Psychiatr. Res. 12 (1975) 189-198.

[29] F.B. Horak, D.M. Wrisley, J. Frank, The balance evaluation systems test (BESTest) to differentiate balance deficits, Phys. Ther. 89 (2009) 484-498.

[30] A.L. Leddy, B.E. Crowner, G.M. Earhart, Functional gait assessment and balance evaluation system test: reliability, validity, sensitivity, and specificity for identifying individuals with Parkinson disease who fall, Phys. Ther. 91 (2011) 102-113.

[31] M.B. Hinman, Factors affecting reliability of the Biodex Balance System: a summary of four studies, J. Sport Rehabil. 9 (2000) 240-252.

[32] S.B. Jonasson, M.H. Nilsson, J. Lexell, Psychometric properties of four fear of falling rating scales in people with Parkinson's disease, BMC Geriatr. 14 (2014) 66.

[33] B.L. Arnold, R.J. Schmitz, Examination of balance measures produced by the biodex stability system, J. Athl. Train. 33 (1998) 323-327.

[34] T. Sieri, G. Beretta, Fall risk assessment in very old males and females living in nursing homes, Disabil. Rehabil. 26 (2004) 718-723.

[35] S. Marzolini, P. Oh, W. McIlroy, D. Brooks, The effects of an aerobic and resistance exercise training program on cognition following stroke, Neurorehabil. Neural Repair 27 (2013) 392-402.

[36] C.M. Nascimento, J.R. Pereira, L.P. de Andrade, M. Garuffi, L.L. Talib, O.V. Forlenza, et al., Physical exercise in MCI elderly promotes reduction of proinflammatory cytokines and improvements on cognition and BDNF peripheral levels, Curr. Alzheimer Res. 11 (2014) 799-805.

[37] J.V. Jacobs, J.S. Lou, J.A. Kraakevik, F.B. Horak, The supplementary motor area contributes to the timing of the anticipatory postural adjustment during step initiation in participants with and without Parkinson's disease, Neuroscience 164 (2009) 877-885.

[38] Z.S. Nasreddine, N.A. Phillips, V. Bedirian, S. Charbonneau, V. Whitehead, I. Collin, et al., The Montreal Cognitive Assessment, MoCA: a brief screening tool for mild cognitive impairment, J. Am. Geriatr. Soc. 53 (2005) 695-699.

[39] L.A. King, D.S. Peterson, M. Mancini, P. Carlson-Kuhta, B.W. Fling, K. Smulders, et al., Do cognitive measures and brain circuitry predict outcomes of exercise in Parkinson Disease: a randomized clinical trial, BMC Neurol. 15 (2015) 218.

[40] S.J. Fleck, Periodized strength training: a critical review, J. Strength Cond. Res. 13 (1999) 82-89.

[41] C. Ugrinowitsch, G.W. Fellingham, M.D. Ricard, Limitations of ordinary least squares models in analyzing repeated measures data, Med. Sci. Sports Exerc. 36
(2004) 2144-2148.

[42] J. Cohen, Statistical Power Analysis for the Behavioral Sciences, L Erlbaum Associates, Hillsdale, NJ, 1988, pp. 29-35.

[43] S.M. Haley, M.A. Fragala-Pinkham, Interpreting change scores of tests and measures used in physical therapy, Phys. Ther. 86 (2006) 735-743.

[44] S.N. Robinovitch, B. Heller, A. Lui, J. Cortez, Effect of strength and speed of torque development on balance recovery with the ankle strategy, J. Neurophysiol. 88 (2002) 613-620.

[45] J.V. Jacobs, D.M. Dimitrova, J.G. Nutt, F.B. Horak, Can stooped posture explain multidirectional postural instability in patients with Parkinson's disease? Exp. Brain Res. 166 (2005) 78-88.

[46] J.F. Yang, D.A. Winter, R.P. Wells, Postural dynamics of walking in humans, Biol. Cybern. 62 (1990) 321-330.

[47] H. Morita, M. Shindo, S. Ikeda, N. Yanagisawa, Decrease in presynaptic inhibition on heteronymous monosynaptic Ia terminals in patients with Parkinson's disease, Mov. Disord. 15 (2000) 830-834.

[48] C.L. Chung, S. Thilarajah, D. Tan, Effectiveness of resistance training on muscle strength and physical function in people with Parkinson's disease: a systematic review and meta-analysis, Clin. Rehabil. 30 (2016) 11-23.

[49] Y.Y. Liao, Y.R. Yang, S.J. Cheng, Y.R. Wu, J.L. Fuh, R.Y. Wang, Virtual reality-based training to improve obstacle-crossing performance and dynamic balance in patients with Parkinson's disease, Neurorehabil. Neural Repair 29 (2015) 658-667.

[50] M.H. Nilsson, G.M. Hariz, S. Iwarsson, P. Hagell, Walking ability is a major contributor to fear of falling in people with Parkinson's disease: implications for rehabilitation, Parkinsons Dis. 2012 (2012) 713236.

[51] Y. Winter, S. von Campenhausen, M. Arend, K. Longo, K. Boetzel, K. Eggert, et al., Health-related quality of life and its determinants in Parkinson's disease: results of an Italian cohort study, Parkinsonism Relat. Disord. 17 (2011) 265-269.

[52] E. Rosenthal, L. Brennan, S. Xie, H. Hurtig, J. Milber, D. Weintraub, et al., Association between cognition and function in patients with Parkinson disease with and without dementia, Mov. Disord. 25 (2010) 1170-1176.

[53] R.Y. Lo, C.M. Tanner, K.B. Albers, A.D. Leimpeter, R.D. Fross, A.L. Bernstein, et al., Clinical features in early Parkinson disease and survival, Arch. Neurol. 66 (2009) 1353-1358.

[54] O. Segev-Jacubovski, T. Herman, G. Yogev-Seligmann, A. Mirelman, N. Giladi, J.M. Hausdorff, The interplay between gait, falls and cognition: can cognitive therapy reduce fall risk, Expert Rev. Neurother. 11 (2011) 1057-1075.

[55] B.W. Fling, M.L. Dale, C. Curtze, K. Smulders, J.G. Nutt, F.B. Horak, Associations between mobility, cognition and callosal integrity in people with parkinsonism, NeuroImage Clin. 11 (2016) 415-422.

[56] R. Morris, S. Lord, J. Bunce, D. Burn, L. Rochester, Gait and cognition: mapping the global and discrete relationships in ageing and neurodegenerative disease, Neurosci. Biobehav. Rev. 64 (2016) 326-345.

[57] F. Li, P. Harmer, K. Fitzgerald, E. Eckstrom, R. Stock, J. Galver, et al., Tai chi and postural stability in patients with Parkinson's disease, N. Engl. J. Med. 366 (2012) 511-519.

[58] F.J. David, J.A. Robichaud, S.E. Leurgans, C. Poon, W.M. Kohrt, J.G. Goldman, et al., Exercise improves cognition in Parkinson's disease: the PRET-PD randomized, clinical trial, Mov. Disord. 30 (2015) 1657-1663.

[59] J. Prodoehl, M.R. Rafferty, F.J. David, C. Poon, D.E. Vaillancourt, C.L. Comella, et al., Two-year exercise program improves physical function in Parkinson's disease: the PRET-PD randomized clinical trial, Neurorehabil. Neural Repair 29 (2015) $112-122$ 